DOI: https://doi.org/10.17648/2238-037X-trabedu-v29n1-13888

(c) (1) https://creativecommons.org/licenses/by/4.0/

\title{
O SABER DOCENTE SOBRE A TEORIA HISTÓRICO-CULTURAL
}

\author{
Teaching knowledge on Historical-Cultural Theory
}

\author{
MARINHO, Amanda Cristina Ferreira ${ }^{1}$ \\ CORDEIRO, Suzi Maria Nunes ${ }^{2}$ \\ FERREIRA, Helaine Patrícia ${ }^{3}$
}

\begin{abstract}
Resumo
O presente artigo busca compreender acerca da Teoria Histórico-Cultural, assim como sua aplicabilidade pedagógica junto aos professores da rede municipal de ensino de uma escola no norte do estado do Paraná. O objetivo consiste em identificar as representações sociais de professoras da rede municipal de ensino sobre a teoria vygotskyana, a fim de compreender como é significado pelas docentes e como isso impacta em suas atuações. Para tanto, foram realizadas entrevistas com sete professoras utilizando um questionário semiestruturado. As interpretações foram fundamentadas pela Teoria das Representações Sociais (TRS) a fim de se investigar como se formam os conhecimentos comuns no cotidiano dos sujeitos. $O$ estudo justifica-se pela necessidade de demonstrarmos a importância do trabalho de Lev Vygotsky para que os (futuros) docentes reflitam sobre o (des)conhecimento do mesmo e como isso implica na maneira de mediarem o ensino. A problemática consiste em responder ao questionamento: quais são os conhecimentos das educadoras referentes à Teoria Histórico-Cultural? Nessa análise constatou-se que há necessidade de formação continuada para as professoras entrevistadas, visto que as participantes não têm conhecimento dos conceitos centrais do sociointeracionismo, além de se confirmar a hipótese da existência da dicotomia entre teoria e prática que se estabelece após a formação docente, o que torna o trabalho pedagógico vago.
\end{abstract}

Palavras-chave: Vygotsky. Mediação. Representações sociais.

\section{ABstract}

This article seeks to comprise the Historical-Cultural Theory as well as its pedagogical applicability to teachers of the municipal school network of a school in the northern State of Paraná. The aim is to identify the social representations of teachers of the municipal school system on Vygotsky theory with regard to understand how these representations make sense to them and how affect their actions. For this purpose were carried out interviews with seven teachers using a semi-structured questionnaire. The interpretations were based on the Social Representation Theory (SRT) in order to ascertain how common knowledge is formed in the daily lives of the subjects. The study is justified by the need to present the relevance of Lev Vygotsky's work so that forthcoming teachers reflect on the knowledge or the lack of it and how it implies in the way they intervene in their teaching. The issue consists in responding the question: What do educators comprehend concerning to Historical-Cultural Theory? In this analysis has been verified the prominence of continuous training for teachers interviewed, bearing in mind that these participants do not have understanding of the main concepts of interactionist perspective. Furthermore has been confirmed the hypothesis of the dichotomy between theory and practice that is established after the teacher training, which makes the pedagogical work depthless.

\footnotetext{
${ }^{1}$ Acadêmica do curso de Pedagogia da UniCesumar, bolsista do Programa Institucional de Bolsas de Iniciação Científica pela linha de Psicologia Educacional. E-mail: amandacristinamarinho@gmail.com

${ }^{2}$ Pedagoga formada pela Universidade Estadual de Maringá (UEM), Especialista em Psicologia Clínica e Institucional pela mesma instituição e Especialista em EaD e as Novas Tecnologias da Educação pela UniCesumar. Doutora em Educação pela UEM. Professora de Pedagogia na UniCesumar. E-mail: prof-suzi@hotmail.com

${ }^{3}$ Pedagoga e Especialista em Educação pela UEM. Professora de Graduação e Pós-Graduação da UniCesumar. Tutora do Curso de Pedagogia a Distância na Universidade Estadual de Maringá (NEAD-UEM). E-mail: helaine.ferreira@unicesumar.edu.br
}

Trabalho \& Educação | v.29 | n.1 | p.111-123 | jan-abr | 2020 
Keywords: Vygotsky. Mediation. Social representations.

\section{INTRODUÇÃO}

A presente pesquisa aborda a Teoria Histórico-Cultural proposta pelo psicólogo russo Lev Semionovich Vygotsky (*1896-1934t). O intuito, ao investigarmos esse objeto abstrato, é constatarmos a aplicação dessa teoria pelos professores da rede municipal de ensino do Estado do Paraná em sua prática pedagógica. São utilizadas obras do próprio autor e de seus colaboradores que a elaboraram com base no materialismo Histórico-Dialético, desenvolvendo uma teoria Sociointeracionista em que se entende 0 desenvolvimento e a aprendizagem dos seres humanos por meio de trocas e as relações socioculturais que são, no contexto escolar, mediadas pelos docentes. Essa teoria veio a ser amplamente difundida após a morte de Vygotsky e chegou ao Brasil apenas por volta de 1970. Nos anos de 1980, começou a fundamentar propostas curriculares e atualmente é utilizada em muitas escolas do Estado do Paraná.

Diante desse contexto, o objetivo da presente pesquisa consiste em identificar as representações sociais de professoras que atuam nos anos iniciais do ensino fundamental na rede municipal de ensino do Estado do Paraná sobre a teoria vygotskyana, a fim de compreender como suas significações repercutem na ação pedagógica.

Como metodologia realizamos entrevistas semiestruturadas com sete professoras, utilizando também o questionário sociodemográfico. As análises dos dados coletados foram realizadas por meio da Teoria das Representações Sociais (TRS) que investiga como se formam os conhecimentos comuns no cotidiano dos sujeitos. Portanto, este estudo é de natureza qualiquantitativa e se caracteriza como um estudo de campo, em que são realizadas as entrevistas.

O estudo justifica-se pela necessidade de demonstrarmos a importância do trabalho de Lev Vygotsky para que os (futuros) docentes reflitam sobre o (des)conhecimento do mesmo e como isso implica na maneira de mediarem o ensino. Portanto, buscamos responder à seguinte problemática: Quais são as representações sociais dos educadores referentes à Teoria Histórico-Cultural? Nossa hipótese paira sobre a ideia de que há uma dicotomia entre a teoria e a prática na formação dos professores, logo, o que eles entendem sobre mediação e demais conceitos da teoria investigada não é aplicado na prática docente.

\section{DesenVolvimento e APRENDizAGEM NAS RELAÇões SOCIAIS}

A Teoria Histórico-Cultural também é considerada uma teoria Sociointeracionista, pois acredita que o desenvolvimento humano ocorre com as trocas sociais. Apesar da morte precoce, Lev Vygotsky elaborou muitos conceitos importantes para compreender 0 percurso do desenvolvimento humano e infantil, e até os dias atuais suas contribuições ajudam educadores no mundo todo. Nesta pesquisa, destacamos os conceitos que mais contribuem para o trabalho pedagógico. A teoria de Vygotsky trouxe novas perspectivas e modificações no trabalho do professor que se constitui como mediador entre 0 conhecimento e o aluno. 
Por meio das interações entre discentes e docentes, a aprendizagem pode se encaminhar para níveis mais elevados que a criança não conseguiria alcançar sozinha (FINO, 2001). Essa teoria não visa solucionar todos os problemas educacionais nem se tornar um manual de instruções didáticas a serem seguidas, mas um instrumento de reflexão para o professor quanto às suas práticas, se estas estão comprometidas com a formação plena desses alunos ou se é chegado o momento de buscar novas alternativas para que estes se apropriem do conhecimento.

As relações sociais tanto enfatizadas por Vygotsky (1991) têm possibilitado a acumulação bem como a mediação de conhecimentos para as futuras gerações, dando continuidade ao desenvolvimento humano. $O$ autor ainda salienta aspectos relevantes da maturação e da aprendizagem humana:

O desenvolvimento se baseia em dois processos inerentemente diferentes, embora relacionados, em que cada um influencia o outro de um lado a maturação, que depende diretamente do desenvolvimento do sistema nervoso; de outro o aprendizado, que é em si mesmo, também um processo de desenvolvimento (VYGOTSKY, 1991, p. 53).

A aprendizagem se refere ao acúmulo dos conhecimentos e à capacidade de pensar sobre eles; esse conceito não se trata de um ato mecânico visto que há capacidades e funções psicológicas a serem movidas, desde os processos de assimilação, reflexão e acomodação. A aprendizagem só se efetiva se o aluno encontrar possibilidades de generalização e a aplicação destas (VYGOTSKY, 1991).

Desenvolvimento e aprendizagem, mesmo que distintos, estão inter-relacionados, pois, quanto mais a criança adquire conhecimentos, mais ela impulsiona e avança em nível mental, no desenvolvimento e vice-versa. Segundo Vygotsky (1991, p. 57), existe diferença entre a aprendizagem escolar e aquela que ocorre fora da instituição:

A diferença entre o aprendizado pré-escolar e o escolar está no fato de o primeiro ser um aprendizado não sistematizado e o último um aprendizado sistematizado. Porém, a sistematização não é o único fator; há também o fato de que o aprendizado escolar produz algo fundamentalmente novo no desenvolvimento da criança.

A criança, portanto, não pode ser considerada nessa teoria uma folha em branco onde se depositam informações, pois, desde o nascimento, acumula saberes práticos para descobrir o mundo que a cerca e, assim, consegue se adaptar à vida em sociedade, e isso só é possível a partir da convivência com indivíduos mais experientes que possam mediá-la. Quanto ao desenvolvimento, devemos destacar dois níveis: o real e o potencial. O primeiro envolve os processos mentais já concretizados em que a criança realiza tarefas de forma independente, enquanto o nível potencial são processos que ainda não estão completos, mas chegará com o desenvolvimento na medida em que se aprende (VYGOTSKY, 1991).

Entre esses dois níveis encontra-se a denominada Zona de Desenvolvimento Proximal - "A zona de desenvolvimento proximal define aquelas funções que ainda não amadureceram, mas que estão em processo de maturação, funções que amadurecerão, mas que estão presentemente em estado embrionário" (VYGOTSKY, 1991, p. 58). É nessa zona de desenvolvimento que o professor realiza as mediações, pois, entre o que a criança sabe e o que ela pode alcançar, há necessidade da ajuda de um adulto para a criança realizar determinadas atividades. 
A partir desses conceitos, o professor se torna capaz de fazer melhor direcionamento de suas práticas e das atividades a serem desenvolvidas; enquanto mediador de todo processo, tem a responsabilidade de sistematizar a aprendizagem pré-escolar e inserir o aluno no processo histórico-social no qual o conhecimento humano se constitui.

Em oposição às teorias pedagógicas tradicionais, Vygotsky (1991) introduziu novas competências para professores e redefiniu o papel do aluno, trazendo como consequências outras perspectivas curriculares para as escolas. $\mathrm{Na}$ visão sociointeracionista, as trocas sociais são de extrema importância para a aprendizagem do indivíduo, portanto, o professor é mediador e o elo entre o conhecimento e o sujeito.

Ao planejar sua prática pedagógica o professor precisa ter em mente que ele é um - senão o principal - dos mediadores da cultura socialmente valorizada. Ele situa-se entre seu aluno e o conhecimento escolar, com a tarefa de levar o primeiro a se apropriar do segundo (MIRANDA, 2004/2005, p. 15).

Ao assumir esse papel de mediador, o professor não pode se contentar com 0 conhecimento superficial, transmitindo apenas informações insignificantes, causando deficiência na formação do aluno. Para efetivação do trabalho pedagógico, necessita tomar como ponto de partida aquilo que o educando já sabe a fim de sistematizar e fundamentar cientificamente esses saberes.

As novas configurações sociais e de ensino têm exigido cada vez mais que o professor saia de sua zona de conforto e busque novas propostas e didáticas para ser um mediador mais eficiente; cabe a ele refletir e ter consciência da sua responsabilidade em formar a criança para viver em sociedade, além de desenvolver todas as capacidades cognitivas desta que ainda estão emergindo.

Ao conceituar a Zona de Desenvolvimento Proximal, Vygotsky (1991) fundamentou a atuação docente enquanto mediador entre o conhecimento científico e 0 aluno. A partir desse conceito, o trabalho pedagógico começou a ser indispensável na formação humana (VYGOTSKY, 1991). "Sendo assim, a ZDP se refere ao desenvolvimento em processo, que está por se consolidar. Para tanto, a participação do outro mais experiente é fundamental, pois resulta no desenvolvimento de formas culturalmente apropriadas" (MIRANDA, 2004/2005, p. 7). Ao receber a mediação pedagógica, a criança poderá realizar atividades que não conseguiria fazer sozinha, portanto, se mediada, ela pode avançar essa realização em nível cognitivo.

O professor precisa estar atento a essas questões ao preparar seu planejamento, pois não é viável focar nas atividades que a criança já sabe realizar, esses processos já estão acabados e não contribuem para o desenvolvimento cognitivo do sujeito. $\mathrm{Em}$ contrapartida, o trabalho na ZDP visa a ações futuras bem como à independência da criança quanto esta generaliza e intemaliza aquilo que aprendeu. "Dessa forma, aquilo que o aluno domina é apenas um ponto de partida para alcançar a zona de desenvolvimento próximo, a qual é alcançada mediante situações adequadas de aprendizagem" (MIRANDA, 2004/2005, p. 8).

Portanto, os processos de aprendizagem se efetivam nas relações entre seus participantes, e o professor, por meio da ZDP, direcionará os conteúdos e objetivos a serem alcançados dentro da disponibilidade cognitiva da criança em determinado momento, enquanto o aluno interpretará e dará significado a esses conhecimentos e, em um processo de assimilação, acomodará e modificará os antigos e novos 
conhecimentos. Martins (1997, p. 6) destaca a importância dessas interações em sala de aula:

\begin{abstract}
Vygotsky aponta que construir conhecimento implica numa ação partilhada, que implica num processo de mediação entre sujeitos. Nessa perspectiva, a interação social é condição indispensável para a aprendizagem. A heterogeneidade do grupo enriquece o diálogo, a cooperação e a informação, ampliando consequentemente as capacidades individuais. As relações sociais se convergem em funções mentais (MARTINS, 1997, p. 6).
\end{abstract}

Transformar teorias em ações não é tarefa simples, cabe ao professor buscar interpretar e trazer esses conceitos para sua realidade, pois como mediador compreender o aluno em sua complexidade é imprescindível, bem como fazer da atuação na Zona de Desenvolvimento Proximal uma estratégia facilitadora do trabalho pedagógico.

Diante do exposto, pretendemos identificar os conhecimentos de professores da rede pública sobre a Teoria Histórico-Cultural e suas aplicabilidades como mediadores e facilitadores dos processos de ensino e de aprendizagem.

\title{
3. Procedimentos metodológicos
}

Para que possamos ter embasamento teórico, a fim de discutirmos acerca da teoria Histórico-Cultural, utilizamos a pesquisa bibliográfica. Cervo e Bervian (1983, p. 55) salientam que a pesquisa bibliográfica "[...] pode ser realizada independentemente ou como parte da pesquisa descritiva ou experimental. Ambos os casos buscam conhecer e analisar as contribuições culturais ou científicas do passado existente sobre um determinado assunto, tema ou problema". Nossa pesquisa bibliográfica complementou as entrevistas, pois estas ajudaram na compreensão de conceitos significativos acerca do objeto de pesquisa.

As ações em campo foram norteadas pela Teoria das Representações Sociais (TRS), de Serge Moscovici ( $\left.{ }^{*} 1925-2014 t\right)$. Essas representações são construídas por grupos sociais, e esses conceitos influenciam como os sujeitos agirão e se comportarão bem como a interpretação que estes farão sobre o mundo. Diante do exposto, a TRS ajuda a identificar o que de fato o sujeito compreende do objeto de pesquisa, em nosso caso, o que as professoras concebem por Teoria Histórico-Cultural. Nesse ínterim, realizamos entrevistas semiestruturadas com sete professoras dos anos iniciais do ensino fundamental de uma escola pública em uma cidade do norte do Estado do Paraná.

A cidade conta com 1.862 habitantes, de acordo com o último censo do IBGE (2010). De acordo com o mesmo censo, a taxa de escolarização dos alunos entre seis a 14 anos é de $99,6 \%$. O número de matrículas em 2015 foi cerca de 283 crianças nos anos iniciais do ensino fundamental que apresentou nota 5,3 no Índice de Desenvolvimento da Educação Básica (IDEB) (IBGE, 2010).

Quanto à estrutura, é uma escola de tamanho razoável, registrando 150 matrículas no ano de 2018. Na gestão da escola, há uma diretora que conta com o auxílio de duas pedagogas, uma em cada período; ambas foram indicadas pela própria diretora da instituição e efetivadas por meio de concurso público para atuarem como docentes. Além disso, há professoras específicas para cada atividade: artística, apoio em contraturno e atividades recreativas; conta-se com 13 docentes, três estagiárias que atuam principalmente nas turmas de alfabetização, além de 20 funcionários distribuídos entre merendeiras e auxiliar de limpeza. 
As entrevistas contaram com dez questões sobre a Teoria Histórico-Cultural e as ações pedagógicas das participantes. A partir delas, identificamos as representações sociais dos sujeitos sobre o tema em questão e compreendemos as práticas destes em sala de aula. Para Triviños (1987), a entrevista semiestruturada possibilita não só a descrição dos fenômenos sociais, mas também a sua explicação e a compreensão de sua totalidade, além de manter a presença consciente e atuante do pesquisador no processo de coleta de dados. A análise dos dados tem caráter qualitativo, pois as respostas dos professores foram transcritas e averiguadas a partir da TRS.

A instituição se encontra em região central, atende a crianças das zonas rurais e urbana, ofertando do primeiro ao quinto ano nos períodos matutino e vespertino. Os nomes das docentes foram preservados e representados pela letra $A$, seguida de um número. $A$ idade média das entrevistadas é de 48 anos, trabalham em torno de $30 \mathrm{~h}$ horas semanais, atendendo do primeiro ao quarto ano do ensino fundamental em salas regulares. Duas entrevistadas trabalham também como pedagogas nos períodos em que não ministram aulas, apenas uma exerce outra atividade além da docência.

A formação apresentada pelas entrevistadas foi bastante variável: uma possui apenas magistério; cinco, licenciatura em Pedagogia; apenas uma possui duas licenciaturas (uma em Pedagogia e outra em Letras com habilitação em Inglês).

Essas professoras atuam na docência no mínimo há cinco e no máximo há 20 anos. Nos últimos dois anos, seis delas fizeram curso de aperfeiçoamento do Pacto Nacional pela Alfabetização na Idade Certa (PNAIC), mas apenas duas delas realizaram especialização em Libras e Gestão Escolar nesse mesmo período de tempo. Todas as participantes possuem entre uma a quatro especializações, algumas em comum: Educação Especial, Gestão Escolar e Psicopedagogia. Outras variantes também ocorreram como Ética, Cidadania e Gestão de Pessoas; Neuropedagogia; Educação, Pobreza e Desigualdade Social e Deficiência Mental.

\section{Resultados e discussões}

Em entrevista, questionamos as professoras se, durante o curso de graduação, elas tiveram algum contato com a Teoria Histórico-Cultural. Assim, pudemos identificar o que conhecem do assunto, sobre a zona e os níveis de desenvolvimento descritos por Vygotsky e se contribuem para suas práticas docentes.

As respostas obtidas foram vagas, a maioria das educadoras não se lembra de ter contato com as obras de Lev Vygotsky, num total de três professoras; vejamos um exemplo: "Não me lembro. Conheço algumas coisas, mas no momento, assim, não dá pra citar muita coisa, não dá pra citar" (A1). Outra professora também tentou defini-la:

Sim a gente tem tanto em Letras como em Pedagogia, principalmente que... ela abrange a parte das... didáticas né? Dentro das disciplinas e no dia a dia na escola, ai o que a gente procura é fazer de acordo com a vivência do aluno né? Pra tá construindo junto com ele (A6).

O trabalho de Lev Vygotsky não teve como foco elaborar didáticas, seu principal objetivo foi unir os aspectos biológicos aos socioculturais que formam os seres humanos na tentativa de compreender a complexa função do intelecto; segundo o autor, esse processo não nasce pronto, na verdade ele é construído ao longo das relações sociais por processos externos e intrapsíquicos (REGO, 1995). Portanto, não se trata de estar 
apenas construindo algo com o aluno, pois este é um ser ativo que necessita interiorizar conhecimentos, modificando suas funções psicológicas superiores.

Por fim, uma professora afirmou não ter entrado em contato: "Não, muito pouco, porque não tive na faculdade" (A7). Dessa forma, das sete entrevistadas, apenas duas tinham uma definição do que é a Teoria Histórico-Cultural. As evidências mostram que as docentes não têm conhecimento sobre o assunto, logo, não há uma representação social.

Seguindo para a próxima questão na intenção de explorarmos o conhecimento das participantes, tentamos entender o que estas conhecem sobre a Zona de Desenvolvimento Proximal e os níveis descritos por Lev Vygotsky. Contudo, a maioria não se manifestou acerca dessa questão: "Nossa, no momento eu não me lembro" (A5). Em consonância, A3 afirmou: "Eu não lembro desse negócio do Vygotsky não, lembro que tinha ele, mas não... Deve contribuir muito".

Percebemos algumas lacunas na formação dessas professoras, o que se torna preocupante quando pensamos na atuação enquanto mediadoras. Torna-se necessário o conhecimento sobre as relações socioculturais para que possam interagir enquanto sujeitos sociais responsáveis por realizar a mediação entre o saber historicamente construído pelos homens, pois, como professoras, elas são os sujeitos mais experientes culturalmente dentro das interações sociais com o aluno (VYGOTSKY, 1991).

Outras questões realizadas nos ajudam a compreender como elas interpretam e utilizam, em sua atuação, aspectos abordados por Vygotsky (1991). Para tanto, perguntamos: "Para você o que é um sujeito histórico e cultural?" "O que é desenvolvimento e aprendizagem para você?" "Você acredita que o brinquedo e o brincar são importantes para a criança? Por quê? Você os utiliza?". Novamente obtivemos respostas dispersas e confusas.

Primeiro, as docentes tentaram definir o que seria um sujeito histórico e cultural: "[...] é aquele que convive com os outros, que tem a cultura dela [...]" (A4). É na interação com os adultos que a criança será introduzida na cultura humana e consequentemente no conhecimento, a partir disso, a criança passa a interpretar o mundo partindo do aspecto biológico para as funções psicológicas superiores construídas com a ajuda de um adulto (LURIA, 2001).

Já A1 trouxe o conceito de sujeito histórico para um âmbito cronológico, vejamos: "Ai! Acho que é um sujeito que compreende a [...] sua história, a história do mundo em que ele vive, é... as culturas dos grupos, dos grupos onde ele atua" (A1). O termo histórico na teoria vygotskyana está relacionado ao desenvolvimento humano, à capacidade do ser humano de construir instrumentos que medeiam sua relação com o mundo, ajudando-o a construir conhecimentos ao longo do tempo (LURIA, 2001). O que torna o sujeito histórico não é compreender a história do mundo, mas pertencer a uma espécie em contínuo desenvolvimento, portanto, podemos afirmar que todas as pessoas são seres históricos.

Inicialmente, a criança responde a estímulos, e a experiência que esta tem com o mundo é puramente biológica, instintiva. É por interações com um adulto capaz de mediá-la que a criança terá acesso à cultura historicamente construída, e nessas constantes trocas sociais é que se formam os processos psicológicos nos sujeitos (LURIA, 2001).

O conceito de "histórico" e "cultural" são amplamente populares, assim, podemos considerá-los termos que têm uma definição para o senso comum e para os grupos 
sociais que partilham tais representações, todavia isso não significa que essa definição condiz verdadeiramente com a obra de Lev Vygotsky (MOSCOVICI, 2015). Percebemos que nenhuma professora conseguiu estabelecer consonância entre os dois conceitos apresentados em um nível mais amplo a fim de fundamentá-los melhor.

Em um segundo momento, as participantes também tentaram definir o que vinham a ser desenvolvimento e aprendizagem, estes foram definidos como sinônimos pelas participantes; vejamos alguns exemplos: "Desenvolvimento é todo processo de [...] de uma aprendizagem mesmo do aluno, de aquisição de habilidades, de [...] é experiências [...] mais ou menos isso" (A1).

A única resposta que se divergiu das demais foi de A4, que está correta de acordo com a teoria vygotskyana: "O Desenvolvimento é, eu acredito que ta mais relacionado assim, as etapas que a criança vai passando e vai amadurecendo, vai crescendo e o aprendizado é o que ela vai obtendo de conhecimento [...]". Ela complementa que alguns conhecimentos prévios a criança já traz de fora da escola, contudo, é o seu papel, enquanto docente, que propicia esse "crescimento" do sujeito.

As pessoas estão apoiadas em vários conhecimentos do senso comum, conhecimentos que utilizam constantemente e ainda os renovam de maneira simplificada em razão do momento tecnológico em que vivem e do acesso às mídias e à informação, porém adquirem pouco conhecimento necessário a seus campos de atuação (MOSCOVICI, 2015).

Quanto ao brinquedo e ao brincar, todas definiram como algo importante que auxilia a aprendizagem e principalmente o desenvolvimento motor, mas em brincadeiras com objetivos:

Sim, é muito importante o lúdico, a criança gosta do pegar, gosta do, e brincando eles aprendem muito a gente observa muito isso em sala que eles, eles gostam de brincar e brincando eles vão aprender. Não é "Ah! Hoje eu vou brincar", mas tem que ter um objetivo aquele brincar né? Não é assim brincadeira, eu acho que muita brincadeira tem objetivo, na maioria todas tem né? Mas é muito importante pra criança principalmente no [...] na alfabetização, o lúdico, brincar é muito importante pra eles (A3).

A criança deseja realizar ações que não são disponíveis em sua realidade, portanto, é a partir do lúdico que ela se realiza, imita comportamentos e regras, substitui objetos e seus reais significados. Essa atividade ajuda a criança a direcionar e controlar seu comportamento para atingir um fim determinado (LEONTIEV, 2001).

As entrevistadas A2, A3, A4 e A7 responderam de forma semelhante, dessa forma, temos um grupo que apresenta como representação social do brinquedo e do brincar uma atividade direcionada. As representações têm um alcance muito maior que o aspecto sociológico, visto que são parte de uma construção histórica, cultural e psicológica, esses processos estão interligados para que possamos entender como as pessoas a criam, pois nas interações que estabelecem os sujeitos trazem marcas de sua identidade, modificam representações e recriam representações (JOVCHELOVITH, 1998).

Se bem conhecida pelo professor, a brincadeira pode ser explorada para além do pedagógico, fazendo com que a criança interiorize regras de convivência, interaja socialmente e satisfaça no brinquedo as necessidades de seu cotidiano. A brincadeira também potencializa a ZDP já que a criança realiza atividades que estão além de sua capacidade mental e física, em razão de sua realidade. 
Por fim, foram realizadas várias questões acerca da própria teoria de Vygotsky (1991) bem como sua aplicação no cotidiano das docentes e de seus alunos. As questões abordadas nesta categoria são, respectivamente: "Qual é o papel da cultura no desenvolvimento da criança?" "O que você compreende por mediação? Você a utiliza? Se sim, em qual momento da sua pratica pedagógica?" "A teoria Histórico-Cultural tem suas bases na relação do sujeito com outros sujeitos. Você acredita que essa relação acontece na escola? De que forma? Se sim, elas são importantes? Por quê?" "A criança, ao chegar à escola, já chega com algum conhecimento ou ela é uma tábula rasa?" "Você trabalha com o conhecimento prévio dessa criança? Por quê?".

Segundo o conhecimento socialmente elaborado pelas educadoras, a cultura no desenvolvimento da criança ocupa papel importante, mas sem justificativa: "Ah, muito importante, cultura é tudo que eles têm que desenvolver a essa cultura, é muito importante a cultura, todo tipo de cultura pra uma escola é muito importante, pra uma criança é muito importante, muito importante é o papel, vishi!" (A3). A teoria vygotskyana valoriza o papel da cultura nas relações humanas ao longo do tempo, pois é parte integrante do ser humano, agindo como um instrumento mediador ao longo da história, modificando o comportamento e as organizações sociais (REGO, 1995).

A1 fez uma colocação um tanto interessante ao dizer como a cultura influenciou e ainda influencia as pessoas ao longo do tempo: "Eu acho que é muito importante porque [...] a cultura ela [...] mobiliza um povo, é historicamente a cultura tem uma grande importância, na minha opinião". Observamos como os sujeitos tentam dar forma a determinados conhecimentos para que possam ser compreendidos por si mesmos e pelos grupos de que participam; como já mencionado por Moscovici (2015), as representações necessitam enquadrar o não familiar por meio de uma linguagem compreensível socialmente. Essas considerações também refletem no processo de mediação, vejamos a definição dada pelas docentes:

Mediação é o... 0 processo entre o que a gente quer passar pro aluno, é a relação entre quem ensina e quem aprende. Ah! É constantemente na sala de aula eu me coloco como mediador entre o conhecimento histórico construído e o que a criança já trás de casa, a gente tenta desenvolver isso sendo mediador o que ele já sabe até onde ele quer chegar (A1).

As demais participantes compartilharam das mesmas representações sociais acerca da mediação, ou seja, todas consideram o professor agente mediador que parte dos conhecimentos prévios do aluno, a fim de integrá-lo ao conhecimento sistematizado no contexto escolar.

A motivação, ao elaborar uma representação, nem sempre liga nossas ideais com a realidade, pois a intenção é dar sentido ao mundo de alguma forma, principalmente quando tratamos de assuntos que fogem à nossa compreensão; nesse sentido, é dificultoso manter as relações entre os grupos, pois estes vão deixando de compartilhar uma linguagem em comum, é necessário reconstruir essas ideias e adaptá-las ao consenso de todos os partícipes (MOSCOVICl, 2015).

O primeiro apontamento a fazermos é: mediação está intimamente ligada à Zona de Desenvolvimento Proximal, sem esta não há possibilidade de mediação. Mediar não consiste apenas em diálogos entre aluno e professor, é todo um processo que envolve organização didática, metodológica e avaliativa. Para que esse trabalho realmente ocorra, faz-se necessário conhecer os conceitos que estão em processo; é aqui que o 
docente atua, provendo meios de desenvolver capacidades que permitam o aluno atuar de forma independente, reorganizando seus esquemas mentais.

Todas as entrevistadas consideraram que as relações sociais ocorrem no ambiente escolar tanto com o professor e com as outras crianças:

Ai ela acontece, ela acontece no convívio com as outras crianças, no convívio com as outras pessoas que trabalham dentro da escola né, através das conversas, das brincadeiras, cada um traz. Elas são importantes pra criança poder se desenvolver né (A4).

A TRS no campo escolar ajuda-nos a compreender como as relações entre os sujeitos desse meio se estruturam, visto que são sujeitos com diferentes concepções de mundo dentro de um mesmo ambiente, que, por se tratar de uma instituição pública, também está fortemente influenciado pela política, economia e ideais sociais, atuando nesse sentido seus partícipes que tanto recebem como emitem representações (NAZAR, 2011).

Dando continuidade às questões, as docentes acreditam que as crianças trazem conhecimento prévio de suas vivências, permitindo verificar para onde as professoras necessitam direcionar seu trabalho pedagógico:

O conhecimento prévio ele dá abertura pra você [...] é [...] poder tá investigando de que ponto você pode partir ou o que que falta pra você inserir pra poder começar esse trabalho, de repente a criança ela já tá assim dentro do contexto ali da sala, ela já tá bem é tranquila por exemplo: em vogais, no alfabeto completo então tem coisa que você pode ir além do que você [...] é espera daquela criança, então o conhecimento prévio é você fazer uma avaliação diagnóstica com ela pra você poder ver se [...] você atinge melhor os objetivos com ela (A6).

As demais repostas obtidas também seguem esse raciocínio, formando uma representação social, pois concordam que a criança traz um aprendizado do seu cotidiano, no convívio com outras pessoas. As docentes também acreditam na importância de utilizar esses saberes dos alunos como ponto de partida para a intervenção pedagógica, como um complemento a mais para a aprendizagem da criança. As representações sociais criam um sistema de mediação entre o sujeito e o mundo que o cerca, permitindo que acumule experiências e conhecimentos variados acerca de diferentes assuntos contemporâneos ou já estabelecidos socialmente (MOSCOVICl, 2015).

Quando relacionamos as respostas ao sociointeracionismo, identificamos uma contradição: como essas docentes consideram o conhecimento da vivência da criança se, por outro lado, não conseguem compreender como a cultura influencia nesse processo? Ressaltamos aqui o termo cultura utilizado por Vygotsky (1995), em que a explicita como um produto da vida social e da atividade social do ser humano. Dessa forma, cultura, vivência e aprendizagem estão interligadas, pois a vivência da criança faz parte da sua cultura, é por meio dela que se interpreta o mundo e adquire experiências de vida. Segundo, como não reconhecem a cultura, não podem mediar conhecimentos trazidos pela criança, portanto, sem conhecimentos prévios não há a progressão para o conhecimento científico. A falta de entendimento da Teoria Histórico-Cultural compromete e inviabiliza seu trabalho como um todo.

\section{Conclusão}


É extensa a dimensão da obra deixada por Lev Vygotsky, mesmo em pouco tempo de vida. Analisando seu trabalho, não encontramos soluções definitivas para os paradigmas educacionais, mas a compreensão dos partícipes que formam essa instituição social, a escola, para que possamos inferir no que diz respeito à qualidade da educação, tarefa que requer tempo, participação e reflexão dos sujeitos que atuam nessa área.

A obra de Moscovici (2015) também foi fundamental para compreendermos como e por que as pessoas se organizam socialmente e produzem conhecimentos. No ambiente escolar onde se cruzam várias linguagens, ideias e histórias de vida, a TRS nos permitiu analisar como as pessoas se agrupam e se assemelham para produzirem conhecimentos e lidar com toda a demanda que a educação apresenta. Com essa teoria, compreendemos que não há um saber absoluto, pois as representações sociais nada mais são do que conhecimentos socialmente construídos, ou seja, um grupo elabora um conhecimento sobre determinado objeto que pode ser compartilhado ou refutado por outros grupos, considerando as culturas e identidades destes e demais elementos envolvidos na elaboração de saberes humanos.

Em caso de conhecimentos não compartilhados, pode ser criado um novo sobre o mesmo objeto. Dessa forma, temos muitos conhecimentos elaborados sobre o mesmo objeto e não cabe à TRS julgar qual está certo ou não, mas identificá-los e apresentá-los para propiciar reflexões. Considerando o exposto, foi essencial para nós interpretar e entender como se formam as representações sobre a obra de Lev Vygotsky, além de poder observar como os sujeitos, em um mesmo ambiente, compartilham alguns conceitos e desconhecem a maioria.

Por meio da TRS, conseguimos atingir nossos objetivos com esta pesquisa, ou seja, compreender como a Teoria Histórico-Cultural é conhecida pelas docentes e como isso repercute em sua atuação. Nossa hipótese inicial era de que as professoras não articulariam teoria e prática, desconhecendo as particularidades da Teoria HistóricoCultural. Infelizmente, diante das entrevistas, pesquisas teóricas e práticas e análise dos dados obtidos confrontados com a teoria, confirmamos a nossa hipótese, visto que não há conhecimento sobre a teoria supracitada entre as participantes, apesar de dizerem que aplicam esses conhecimentos no seu dia a dia com os alunos; porém não têm base teórica e científica que justifique suas ações pedagógicas e deem significado às suas práticas pedagógicas, ditas como mediadoras.

Nossa hipótese de que há uma dicotomia entre teoria e prática se confirma na medida em que verificamos as falas sobre a formação das docentes que afirmam ter passado pelo magistério e pelo curso de Pedagogia, em que faz parte das ementas de algumas matérias as obras de Lev Vygotsky ou de seus colaboradores, ainda que de fontes secundárias. Caberia uma nova investigação sobre a formação dessas professoras, a fim de verificar se houve falha por parte das Instituições de Ensino Superior em não ofertar esse conhecimento, o que acreditamos ser pouco provável, mas deixamos essa investigação para novas pesquisas.

Além da graduação, as professoras entrevistadas afirmam ter especializações na área da Educação, em que novamente costuma haver nas ementas de algumas disciplinas as obras originais ou fontes secundárias sobre a Teoria Histórico-Crítica. Dessa forma, a teoria ensinada durante a formação como um todo não se alia à prática, quando essas docentes assumem uma sala de aula. Assim, a teoria é esquecida nas ações pedagógicas como se fossem elementos distintos nos processos de ensino. 
Respondendo, portanto, à questão norteadora da presente pesquisa: Quais são as representações sociais dos educadores referentes à Teoria Histórico-Cultural? Podemos considerar que não há representações sociais das docentes entrevistadas, visto que não é um objeto conhecido por elas. Com base na TRS, podemos afirmar que o grupo não considera a Teoria Histórico-Cultural como significativa para suas ações pedagógicas, visto que não há interesse pela temática.

Para solucionar esse problema, em primeiro lugar as próprias docentes necessitam ter interesse em conhecer e aprender os conhecimentos básicos do campo da educação. Em segundo lugar, a instituição de ensino deve promover discussões sobre a necessidade de se conhecer essa teoria, sua aplicabilidade e a relevância no processo de ensino e de aprendizagem para promoção do desenvolvimento pleno do aluno. Por fim, o Estado necessita investir mais em cursos de formação continuada e atualização pedagógica dos professores da rede pública, de forma efetiva.

Os anos passam, a sociedade muda e as exigências educacionais também, com isso os educadores devem estar atentos para acompanharem essas novas expectativas e aprofundarem seus conhecimentos acerca das teorias atuais, produções acadêmicas e concepções pedagógicas, visando melhorar a qualidade do seu trabalho e da aprendizagem de cada aluno.

\section{REFERÊNCIAS}

CERVO, Amado Luiz; BARVIAN, Pedro Alcino. Metodologia cientifica: Para uso dos estudantes universitários. São Paulo: Mc Graw-Hill do Brasil, 1983.

FINO, Celso Nogueira. Vygotsky e a Zona de Desenvolvimento Proximal (ZDP): três implicações pedagógicas. Revista Portuguesa de educação, Braga, Portugal, v. 14, n. 2, p. 1-13, 2001. Disponível em: $<w w w .3 . u m a . p t / c a r l o s f i n o / D o c u m e n t o s / Z o n a D e s e n v o l v i m e n t o P r o x i m a l . p d f>$. Acesso em: 23 out. 2017.

IBGE. Instituto Brasileiro de Geografia e Estatística. Censo do IBGE 2010. Rio de Janeiro: IBGE, 2010. Disponível em: https:/cidades.ibge.gov.br/brasil/pr/miraselva/ panorama. Acesso em: 26 mar. 2018

JOVCHELOVITCH, Sandra. Representações Sociais: Para uma Fenomenologia dos Saberes Sociais. Psicologia e Sociedade, Florianópolis, v. 10, n. 1, p. 54-68, 1998.

LEONTIEV, Alexis Nikolaevich. Os princípios psicológicos da brincadeira pré-escolar. In: VYGOTSKY, Lev Seminovich; LURIA, Alexander Remonovich; LEONTIEV, Alexis Nikolaevich. Linguagem, desenvolvimento e aprendizagem. São Paulo: Ícone, 2001. p. 119-142.

LURIA, Alexander Remonovich. Vigotskii. In: VYGOTSKY, Lev Seminovich; LURIA, Alexander Remonovich; LEONTIEV, Alexis Nikolaevich. Linguagem, desenvolvimento e aprendizagem. São Paulo: Ícone, 2001. p. 21-38.

MARTINS, João Carlos. Vygotsky e o papel das interações sociais em sala de aula: reconhecer e desvendar - mundo. Idéia, São Paulo, n. 28, p. 111-122, 1997. Disponível em: http://www.crmariocovas.sp.gov.br/pdf/ideias_28_p111-122_c.pdf. Acesso em: 9 out. 2017.

MIRANDA, Maria Irene. Conceitos centrais da teoria de Vygotsky e a prática pedagógica. Ensino em ReVista, Uberlândia, v. 13, n. 1, p. 7-28, jul.2004/jul.2005. Disponível em: www.seer.ufu.br/index.php/emrevista/article/viewe/File/7921/5027. Acesso em: 11 out. 2017.

MOSCOVICI, Serge. Representações sociais investigação em psicologia social. 11. ed. Petrópolis, RJ: Vozes, 2015.

NAZAR, Terezinha Regina Nogueira. Representações sociais de professores dos anos finais do Ensino Fundamental sobre Transtorno de Déficit de Atenção e Hiperatividade (TDAH). 2011. 86 f. Dissertação (Mestrado em Educação) - Universidade Estácio de Sá, Rio de Janeiro, 2011. Disponível em: http://www.fe.ufrj.br/anpedinha2011/trabalhos/PPGEDUCACAO__ ESTACIO_ _ 174.358.11734_trabalho.doc. Acesso em: 10 mar. 2018. 
REGO, Tereza Cristina. Vygotsky: Uma perspectiva histórico-cultural da educação. 10. ed. Petrópolis, RJ: Vozes, 1995.

TRIVIÑOS, Augusto Nibaldo Silva. Introdução à pesquisa em ciências sociais: a pesquisa qualitativa em educação. São Paulo: Atlas, 1987.

VYGOTSKY, Lev Seminovich. A formação social da mente. 4. ed. São Paulo: Martins Fontes, 1991.

VYGOTSKY, Lev Seminovich. Historia del desarrollo de las funciones psíquicas superiores. In:

Obras escogidas. Madri: Visor/MEC, 1995.

Data da submissão: 10/03/2019

Data da aprovação: 18/05/2020 